ALGRANTI, Joaquin. Politica y religión en los márgenes. Nuevas formas de participación social de las mega-iglesias evangélicas en la Argentina. Buenos Aires: Editora Ciccus, 2010, 355 pp.

\title{
INTEGRALISMO Y POLÍTICA DEL ETHOS
}

\author{
Ana Teresa Martinez
}

El libro de Joaquin Algranti, que nos entrega en este formato lo sustancial de su tesis doctoral defendida recientemente en la UBA-Argentina y en la EHESSFrancia, analiza desde diversos puntos de vista el fenómeno de las "mega-iglesias" evangélicas en Argentina. Aunque el trabajo se ubica empíricamente en Buenos Aires, la construcción de objeto que encara Algranti le permite efectivamente elaborar algunas hipótesis que interrogan de manera pertinente y novedosa la relación entre religión y política en la historia y el presente de Argentina. La descripción, el análisis y la argumentación que sostienen el texto son inteligentes y minuciosas, a partir de un entramado teórico y un trabajo de campo complejo, que abre varias perspectivas de análisis al mismo tiempo. El texto parte de la visibilidad pública que han alcanzado estas iglesias desde la década de 1990 en Buenos Aires, para explorar en la historia de su instalación y desarrollo, los procesos que les han permitido presentarse como una opción respecto de la Iglesia Católica, largamente hegemónica en el país. El autor va mostrando cómo el proceso de ocupación de territorio y de visibilización, va acompañado de estrategias de formación de líderes y participación de los creyentes en actividades donde se potencian sus saberes y habilidades. De estos líderes cristianos se espera, al mismo tiempo, que se involucren en todas las áreas de la vida social para promover un cambio que los sitúa en clara analogía con las vertientes integralistas del catolicismo, y en competencia con ellas.

Inspirado ampliamente en el trabajo sociológico de Pierre Bourdieu, el libro tiene - entre otras - la virtud de desarrollar cierta audacia controlada y reflexiva, que le permite sacar provecho de las nociones que le provee aquel autor, pero a la vez, aproximando referencias prima facie incompatibles - de Parsons a Laclau -, hace rendir disponibilidades teóricas implícitas para construir el significado pertinente en cada caso a fin de avanzar en la construcción de su objeto. De esta manera, se da la libertad de reformular explícitamente algunas nociones para el caso y construir nuevas herramientas. En este sentido el texto es un ejemplo sobre lo que puede producir una teoría rica y compleja como la de Bourdieu cuando la subordinamos a las condiciones 
particulares de aplicación, y escapamos así de la "gran teoría", siempre lista para sobrecargar el análisis con pre-comprensiones ontológicas.

Teniendo en cuenta que hasta la década de 1960 el campo religioso argentino se identifica con el de la Iglesia Católica, que de este modo se superpone al campo general del poder y aparece atravesado por las mismas tensiones que el conjunto de la sociedad, Algranti utiliza críticamente la noción de campo para construir un modelo de análisis sincrónico y diacrónico a partir de las sucesivas distribuciones y redistribuciones de capital simbólico y social, permitiendo ver las transformaciones y la "superposición dinámica" de los lugares que ocupan los agentes institucionales religiosos y políticos desde la década de 1960 a la actualidad, período en el que emergen estos agentes religiosos nuevos. De este modo, se nos posibilita seguir las transformaciones en el largo plazo del modo específico de articulación del espacio religioso según la estructura interna de sus relaciones. El crecimiento pentecostal se produce según este análisis, a costa de la heterodoxia católica desplazada y suprimida en la década de 1970, al menos en su visibilidad pública. Al mismo tiempo, se hacen visibles las condiciones de posibilidad y el significado social del integralismo, sea católico o evangélico, de derecha o de izquierda.

$\mathrm{Al}$ estudio relacional de las posiciones le sigue una historia del pentecostalismo que se hace inteligible en este marco ya trazado, siguiendo el proceso de tres iglesias en Argentina y entrando en un análisis de carácter morfológico donde se describen los espacios de pertenencia y autoridad y los pesos diferenciales que han tenido a la hora de ir construyendo una "visión" renovada a partir de la aparición de una nueva generación de pastores, en un proceso que lleva a las iglesias hacia formas propias de intervención política. El análisis morfológico se detiene a trabajar sobre la diferencia entre el círculo de los pastores y los concéntricos de co-pastores, jefes de ministro, supervisores, líderes y comunidad periférica, señalando los niveles de porosidad diferenciales que generan la estructura de pertenencia y autoridad. Es en este análisis que se percibe el lugar social de los cuadros medios y se fundará luego la descripción de la división del trabajo religioso.

Tanto en la topología diacrónica del espacio social argentino que se ensaya en los primeros capítulos como en esta diferenciación de espacios al interior de las iglesias, el análisis del lugar social evidentemente no agota las explicaciones posibles, pero en sociología constituye siempre un dato mayor, que Algranti utiliza muy bien en su texto.

En el tercer abordaje, que se desplaza a la objetivación de los agentes en el ámbito de lo cotidiano, destacan dos conceptos, que el autor trabaja con especial cuidado. En primer lugar, el concepto bourdiano de sufrimiento social, en tanto especificación de las consecuencias biográficas de los cambios estructurales de la década de 1990, vividos como faltas personales en buena medida como efecto del discurso social del momento. Interpretado desde aquí y fundado en su trabajo de campo, Algranti muestra cómo opera en las biografías individuales la posibilidad de manejar esta culpa socialmente construida, externalizándola en la doble figura del diablo como causa externa del mal y del "mundo" como tentación e influencia. Esta externalización permitiría a los sujetos realizar una restauración de sí mismos y la transformación del sufrimiento en capacidades, que pueden 
luego ponerse al servicio de una transformación análoga a la vivida por el agente, en el orden de la sociedad y la cultura. Esta experiencia individual pero a la vez típica sería el lugar desde donde proponer una "Argentina para Cristo".

El segundo concepto, el de adecuación activa, remite a Weber y a los procesos de racionalización religiosa: la elaboración individual del sufrimiento social y la relación con el mundo configuraría un ethos, donde el Evangelio aparecería como el discurso ideológico por encima de todas las ideologías, porque propone valores que se sitúan por fuera $-y$ por encima- de la historia. La política que se construye así desde el ethos, no sería pre-política, sino una que no se dice tal y que precisamente de allí obtiene su eficacia: no es sino "potencia en acto", como dice Algranti, "potencia activa" si quisiéramos hablar como Aristóteles. Es en este punto donde el concepto de "significante vacío" de Laclau permite escapar a conceptualizaciones esencialistas y percibir cómo el evangelismo concentra en sí expectativas y deseos múltiples, de agentes que proceden de experiencias sociales y trayectorias muy diferentes. La división del trabajo religioso organiza las acciones de dos tipos de agentes: los cuadros medios, que serán quienes articulen la demanda en la acción política concreta, y los pastores que realizan una acción política "desde abajo", a fin de conservar la unidad de la feligresía y el capital simbólico propiamente religioso, fundante y polisémico, es decir, abierto a desarrollar sentidos adaptados a las diversas situaciones al "adecuarse". Esta similitud estructural con sus homólogos católicos de mediados del siglo XX (la Jerarquía y la Acción Católica) no parece casual si tenemos en cuenta el conjunto de la investigación. La capacidad que despliega el pentecostalismo para competir con el catolicismo por los espacios de poder no impide ver que se trata de una nueva versión de integralismo religioso, sino más bien la confirma. Pero no parece ser sólo la expresión discursiva de la superposición dinámica de las instituciones y los cuadros religiosos en el conjunto del espacio social, sino también, concomitantemente, una acción política que se niega como tal porque se funda en el ethos, sin mediaciones y se inhabilita desde allí para hablar en los términos de las instituciones de la democracia liberal.

En este análisis minucioso y teóricamente osado, de corte claramente sociológico, que se mueve entre el análisis relacional de posiciones y el de las disposiciones de los agentes, de lo que se habla todo el tiempo es de las Mega-Iglesias pentecostales, y hablando de ellas se aventuran hipótesis sobre la problemática relación entre religión y política en la Argentina contemporánea, una clave central para comprender la historia y los retos ante los que se encuentra el presente político del país.

Ana Teresa Martinez (atmartinez@conicet.gov.ar)

Doutora em Ciências Sociais pela Universidade de Buenos Aires. Diretora do Instituto de Estudos para o Desenvolvimento Social da Universidade Nacional de Santiago del Estero. Pesquisadora do Conicet. 